\section{Presence and possible significance of immunohistochemically demonstrable metallothionein expression in pterygium versus pinguecula and normal conjunctiva}

SEVASTI TSIRONI, ELLI IOACHIM, MELPOMENI MACHERA, MILTIADES ASPIOTIS, NIKI AGNANTI, KONSTANTINOS PSILAS

\begin{abstract}
Purpose To investigate metallothionein (MT) expression in pterygium, pinguecula and normal conjunctiva and define its possible

biochemical pathway of MT synthesis seems interestingly to cross the pathways of cell proliferation, inflammation and immune activation.
\end{abstract} significance in this area of the eye. In order to further elucidate the mechanism of MT expression we correlated it with lymphocyte subpopulations (T4, T8), macrophages (CD68), Langerhans' cells (S100) and the proliferationassociated indices (PCNA, Ki67).

Methods Eighty-five surgically excised pterygia, 15 pingueculae and 20 normal conjunctivae were immunohistochemically studied by the avidin-biotin (ABC) method. A monoclonal antibody (E9) against a conserved epitope of I and II isoforms of MT was used on formalin-fixed, paraffin-embedded tissues. Statistical analysis was performed using the SPSS statistical package.

Results Epithelial MT expression was detected in all 120 cases examined and in most of them both nuclear and cytoplasmic immunoreactivity was present. Nevertheless no statistically significant difference of MT expression was found between the three types of tissue. A statistically significant positive correlation between MT expression and lymphocyte subsets, macrophages and Langerhans' cells was found in pterygium. On the contrary, we did not find any statistical correlation in pinguecula and normal conjunctiva. In all three types of tissues MT expression was also positively correlated with the proliferation-associated indices. Conclusion The data suggest that there is immunohistochemically demonstrable MT expression in the epithelium of pterygium, but also of normal conjunctiva and pinguecula. MT may serve a photoprotective role in this region. In pterygium in particular, the
Key words Conjunctiva, Immunohistochemistry, Metallothionein, Pinguecula, Pterygium

Metallothioneins are a family of heavy metal binding proteins with a large degree of sequence homology that is conserved throughout the animal kingdom. They are cysteine-rich, single-chain proteins of low molecular weight (6000 daltons). ${ }^{1-4}$ There are two isoforms of metallothionein (MT) in mammals: MT1 and MT2. ${ }^{5}$

MT plays a crucial role in metal transport, ${ }^{6-8}$ mineral nutrition ${ }^{9}$ and detoxification of metals and other chemicals, in embryonic development, cellular differentiation and cell proliferation, ${ }^{3,10}$ but also in carcinogenesis.

MT genes are generally highly inducible. MT synthesis is induced by group II b heavy metal ions $^{9,11}(\mathrm{Zn}, \mathrm{Cu}, \mathrm{Kd})$, glucocorticoids, growth factors, cytokines, interferon, interleukin 1, vitamin $\mathrm{D}$, divalent heavy metal hormones and tumour promoters. ${ }^{12,13}$ MTs are not normally expressed constitutively in tissues in amounts detectable by immunohistochemistry, except for a few specific cell types. Furthermore, MTs are implicated in any form of stress or injury (inflammation, ischaemia, ionising radiation, ultraviolet (UV)-damaged DNA, alkylating agent cytotoxicity), providing a cytoprotective mechanism against potential damaging effects of oxygen-derived free radicals. ${ }^{9}$ This is in accordance with recent studies which have indicated photoinduction of MT in mouse skin, but also in human skin in vivo, by UV irradiation. $^{5}$
S. Tsironi

M. Aspiotis

K. Psilas

Department of

Ophthalmology

University of loannina

Medical School

45110 Ioannina, Greece

E. lochiam

M. Machera

N. Agnanti

Department of Pathology

University of loannina

Medical School

45110 loannina, Greece

Dr Elli loachim

Department of Pathology

Medical School

University of Ioannina

45110 loannina, Greece

Tel: +30 651 97520;

+3065199212

Fax: +30651 46209;

+3065199212

e-mail: nagnanti@cc.uoi.gr

Received: 11 February 2000 Accepted in revised form:

1 June 2000 
On the other hand UV radiation has been positively correlated with the formation of pterygium as well as certain other eye diseases. ${ }^{14-16}$ More specifically there is still much controversy concerning the aetiology and pathogenesis of pterygium. Heredity and genetic predisposition, climatic conditions, chronic irritation and immunological mechanisms can induce the disease. ${ }^{16-20}$ But broadband UV radiation $(290-400 \mathrm{~mm}$ ) is probably still the most incriminated factor that has long been implicated in the pathogenesis of pterygium. ${ }^{14,15,21-23}$ Recently, ozone layer depletion has focused attention on the biological consequences of increased UV insolation, and increased prevalence rates for pterygium have been predicted. ${ }^{18,24}$ Under these circumstances further information about the intracellular activities and the biological behaviour of the lesion may be of strong interest.

With these points in mind we investigated in the present study the immunohistochemical expression of MT in a series of 85 pterygia as well as 15 pingueculae, and 20 nasal epibulbar conjunctivae. To further elucidate the mechanism of MT expression we detected immunohistochemically, and also studied the possible correlation of, a number of other factors:

1. PCNA (proliferating cell nuclear antigen) and Ki67 antigen (MIB1), as indicators of cell proliferation.

2. S100 protein as an indicator of Langerhans' cells (antigen presenting cells involved in T-cell activation and delayed type hypersensitivity).

3. T4 and T8 subsets and also CD68 infiltrations (macrophages), as indicators of inflammation.

\section{Materials and methods}

Pterygial tissues were obtained during pterygium surgery of 85 patients in a period of almost 3 years. Nine of these pterygia were recurrent ones. Seventy-six of the patients were in outdoor occupations, in particular agricultural work. Forty were men and 45 were women of ages that varied between 31 and 85 years (mean age 61 years). Except for topical anaesthetic no medicine or other chemical agent was used during pterygium excision. The same surgeon treated all cases.

The control tissues used were nasal epibulbar conjunctivae close to the limbus taken during their cataract or retina surgery from 20 patients (mean age 62 years) with no history of eye disease or use of ocular drugs in the past.

We also used as control tissues pingueculae of 15 patients (mean age 60 years), which were taken either during cataract surgery or during an autonomous pinguecula excision, in cases where the hyperplastic lesion caused problems (irritation, chronic inflammation, dellen or cosmetic annoyance).

All sections of specimens were processed by standard techniques to paraffin wax, after fixation in formalin $10 \%$, stained with haematoxylin and eosin, and viewed. Pterygia were classified as vascular $(26 \%)$, mixed $(60 \%)$ and fibrous (14\%) types.
Table 1. Antibodies used

\begin{tabular}{llll}
\hline Antibodies & Supplier & Dilution & Incubation time \\
\hline Metallothionein (E9) & Dako & $1: 50$ & 1 hour \\
PC-10 & Dako & $1: 50$ & 1 hour \\
MIB1 (Ki-67) & Ylem & $1: 50$ & Overnight $^{a}$ \\
CD8 (T8) & Dako & $1: 50$ & 1 hour \\
CD4 (T4) & Dako & $1: 50$ & 1 hour \\
CD68 & Dako & $1: 50$ & 1 hour \\
S-100 & Dako & $1: 50$ & 1 hour $^{b}$ \\
\hline
\end{tabular}

MT antibody was found by Jasani and Elmes to be immunohistochemically reactive against a conserved epitope shared by the 1 and 2 isoforms of human, rat and horse MT, as tested on formalin-fixed, paraffin-embedded tissues obtained from the species. The antibody is now commercially available in its purified form Dako (Dako, High Wycombe, UK).

${ }^{a}$ With microwave oven antigen retrieval.

${ }^{b}$ Incubation with pronase.

Immunohistochemistry on paraffin sections $4 \mu \mathrm{m}$ thick was performed using the avidin-biotin method as previously described. ${ }^{25}$ The sources and dilution of the antibodies used are shown in Table 1. Non-immune murine serum (Dako) at the same dilution as the primary monoclonal antibody was used for negative control.

\section{Immunohistochemical evaluation}

The evaluation of immunostaining MT expression (nuclear and cytoplasmic) was calculated as a percentage of positive epithelial cells in relation to the total number in representative fields. Nuclear staining for Ki67 and PCNA was estimated as the percentage of positive cells in the total number of epithelial cells. Each sample was first scanned with a low magnification and at least 5 to 10 fields were assessed with a high-power magnification. The distribution (intraepithelial and extraepithelial-stromal cells) and the number of $\mathrm{T}$ helper/inducer (T4, CD4), T cytotoxic/suppressor cells (T8, CD8), macrophages (CD68) and Langerhans' (S100 positive cells) were calculated. The percentage of positive cells in at least 5 high-power representative fields (HPF $\times 40$ objective) was estimated for each sample section. Light microscopy sections were examined in masked fashion by two independent observers. They agreed in the majority of cases (kappa $=0.8$ ). In the remaining cases, a re-estimation was done and final agreement was achieved.

\section{Statistical analysis}

All data were entered into a microcomputer and statistical analysis was performed using the SPSS statistical package. The association of continuous variables was confirmed using non-parametric test for several independent samples: Kruskal-Wallis one-way ANOVA. We also used the Spearman bivariable correlation. $p$ values smaller than 0.05 were considered statistically significant. 


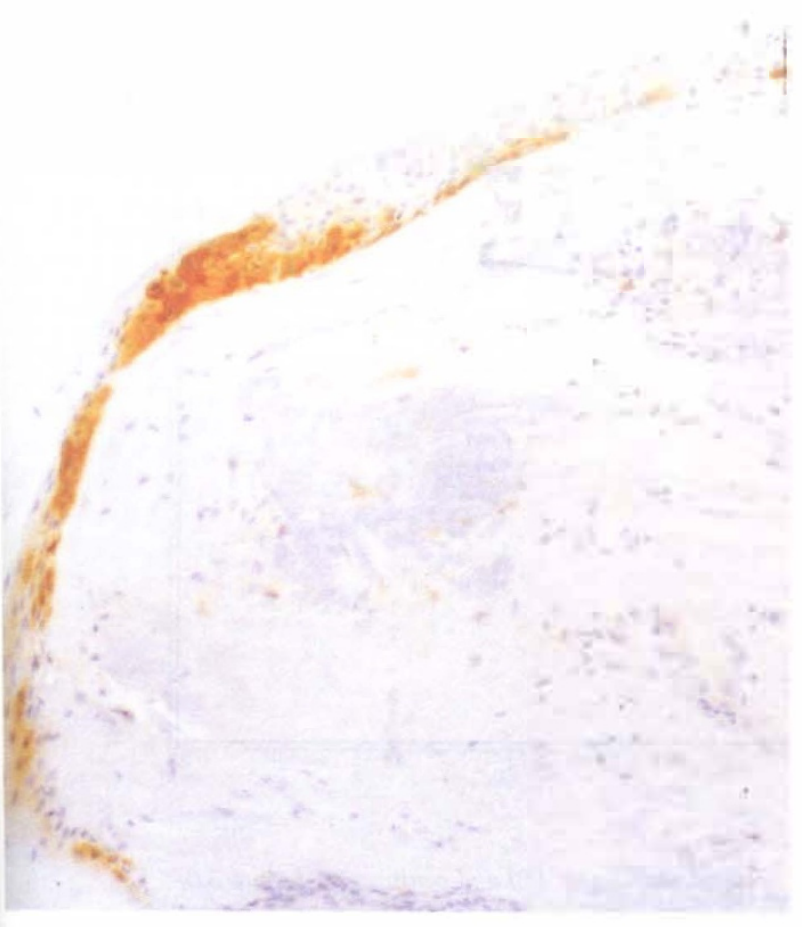

Fig. 1. Metallothionein expression in epithelium of a pterygium ( $A B C$, $\times 100)$.

\section{Results}

The immunohistochemical localisation of MT has shown its rather ubiquitous presence in both cytoplasm and nuclei of the epithelial cells of pterygia (Figs. 1, 2), pingueculae and conjunctivae. MT immunoreactivity was usually confined to the basal layers of the epithelium. T cells expressing the suppressor/cytotoxic phenotype (T8) were found mostly in the basal portion of the epithelium, but also in the upper stroma. The majority of T4 cells were in aggregates mostly under the epithelium. Macrophage (CD68) cell infiltrates were less prominent in epithelium and more in the stroma.

Langerhans' cells (S-100) were found mostly in the

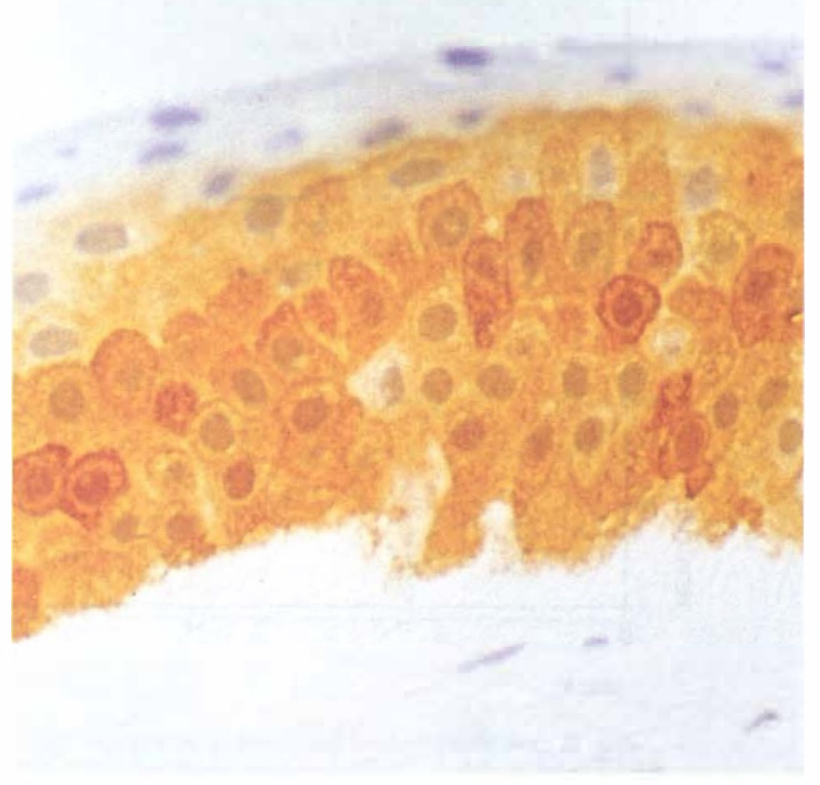

Fig. 2. High-power view of epithelial metallothionein expression in a case of pterygium $(A B C, \times 400)$.

epithelium, particularly in the basal portion. PCNA and Ki67 expression was also mainly observed in the basal portion of the epithelium.

Expression of MT was comparable in normal conjunctiva (mean value: 8.84 , median: 3 ), pinguecula (mean value: 4.41 , median: 4 ) and pterygium (mean value: 7.33, median: 4). (Table 2; Figs. 3, 4) No statistically significant difference in MT expression was observed between pterygium and normal conjunctiva or between pterygium and pinguecula $(p<0.001)$.

In pterygium MT immunopositive cells were positively correlated with epithelial (S100) Langerhans' cells $(r=0.6, p<0.001)$. There was also a positive

Table 2. Mean values, median, range of MT, subpopulation infiltrations and expression of proliferation indices in pterygium, pinguecula and normal conjunctiva

\begin{tabular}{|c|c|c|c|c|c|c|c|c|c|c|}
\hline \multirow[b]{2}{*}{ Tissue } & \multirow[b]{2}{*}{ MT } & \multicolumn{2}{|c|}{$\mathrm{T} 4$} & \multicolumn{2}{|c|}{$\mathrm{T} 8$} & \multicolumn{2}{|c|}{$\mathrm{S} 100$} & \multirow{2}{*}{$\begin{array}{c}\text { CD68 } \\
\text { Stromal }\end{array}$} & \multirow[b]{2}{*}{ PCNA } & \multirow[b]{2}{*}{ Ki67 } \\
\hline & & Epithelial & Stromal & Epithelial & Stromal & Epithelial & Stromal & & & \\
\hline \multicolumn{11}{|c|}{ Pterygium } \\
\hline $\mathrm{M}$ & 7.33 & 0.4 & 5.4 & 2.28 & 3.28 & 5.48 & 1.29 & 2.97 & 6.22 & 1.24 \\
\hline $\mathrm{Me}$ & 4 & 0.2 & 2.4 & 1.6 & 2.6 & 4.3 & 1.2 & 2.2 & 2 & 0.1 \\
\hline Min & 0 & 0 & 0 & 0 & 0 & 0.3 & 0 & 0 & 0 & 0 \\
\hline $\operatorname{Max}$ & 55 & 4.6 & 4.8 & 10.8 & 18.7 & 2 & 6.6 & 15 & 40 & 14 \\
\hline \multicolumn{11}{|c|}{ Pinguecula } \\
\hline M & 4.41 & 0.40 & 4.39 & 2.69 & 2.25 & 0.66 & 0.53 & 1.26 & 3.05 & 0.07 \\
\hline $\mathrm{Me}$ & 4 & 0.2 & 2.4 & 1.8 & 1.5 & 0.6 & 0.55 & 0.4 & 1.7 & 0.01 \\
\hline Min & 0 & 0 & 0 & 0 & 0 & 0 & 0 & 0 & 0 & 0 \\
\hline $\operatorname{Max}$ & 15 & 2.4 & 4.8 & 9 & 6.8 & 1.7 & 1.8 & 7 & 15 & 5 \\
\hline \multicolumn{11}{|c|}{$\begin{array}{l}\text { Normal } \\
\text { conjunctiva }\end{array}$} \\
\hline M & 8.84 & 0.33 & 2.59 & 1.96 & 2.37 & 0.38 & 0.43 & 1.07 & 3.55 & 0.04 \\
\hline Me & 3 & 0.2 & 2 & 1 & 2 & 0.2 & 0.25 & 0.8 & 0.5 & 0.01 \\
\hline Min & 0 & 0 & 0 & 0 & 0 & 0 & 0 & 0 & 0 & 0 \\
\hline Max & 65 & 1.2 & 10 & 9 & 7.6 & 1.8 & 1.4 & 2.8 & 15 & 0.5 \\
\hline
\end{tabular}

M, mean; Me, median; Min, minimum; Max, maximum. 


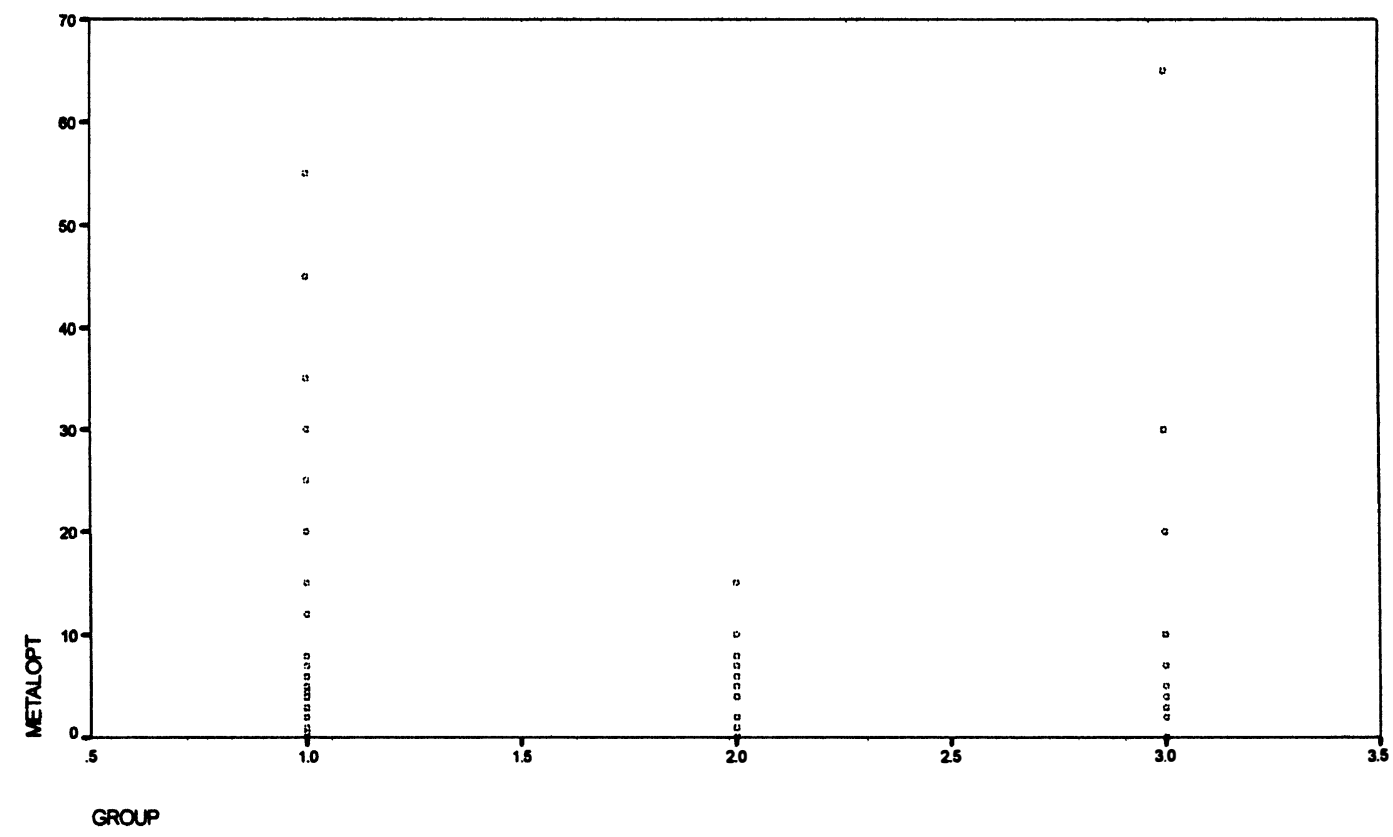

Fig. 3. Metallothionein expression in pterygium (group 1.0), pinguecula (group 2.0) and conjunctiva (group 3.0).

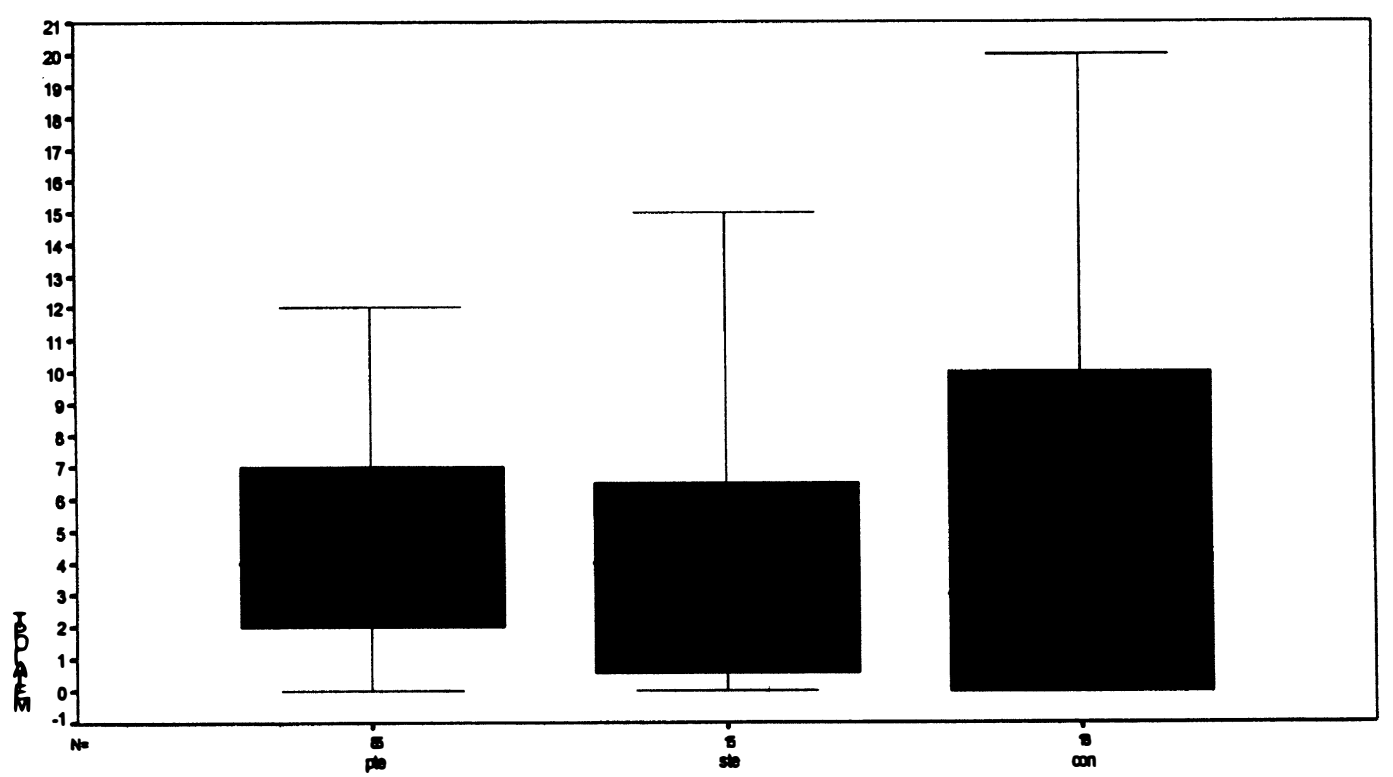

Fig. 4. Metallothionein expression in pterygium (pte), pinguecula (ste) and conjunctiva (con).

Table 3. Correlation of various cells densities and MT expression in pterygium, pinguecula and conjunctiva

\begin{tabular}{|c|c|c|c|c|c|c|}
\hline$\overline{\mathrm{T} 8}$ & \multicolumn{2}{|c|}{ Pterygium-MT } & \multicolumn{2}{|c|}{ Pinguecula-MT } & \multicolumn{2}{|c|}{ Conjunctiva-MT } \\
\hline Epithelial & $r=0.3$ & $p=0.01$ & $r=0.3$ & $p=0.2$ & $r=0.3$ & $p=0.1$ \\
\hline Stromal & $r=0.2$ & $p=0.06$ & $r=0.4$ & $p=0.1$ & $r=0.3$ & $p=0.1$ \\
\hline \multicolumn{7}{|l|}{ CD68 } \\
\hline Epithelial & $r=0.4$ & $p<0.001$ & $r=0.4$ & $p=0.1$ & $r=0.2$ & $p=0.3$ \\
\hline Stromal & $r=0.3$ & $p<0.04$ & & & & \\
\hline \multicolumn{7}{|l|}{ S100 } \\
\hline Epithelial & $r=0.6$ & $p<0.001$ & $r=0.2$ & $p=0.3$ & $r=0.2$ & $p=0.2$ \\
\hline Stromal & $r=0.01$ & $p=0.1$ & $r=0.05$ & $p=0.8$ & $r=0.4$ & $p=0.05$ \\
\hline Ki67 & $r=0.5$ & $p<0.001$ & $r=0.4$ & $p=0.07$ & $r=0.4$ & $p=0.04$ \\
\hline PCNA & $r=0.4$ & $p<0.001$ & $r=0.5$ & $p=0.05$ & $r=0.8$ & $p<0.001$ \\
\hline \multicolumn{7}{|l|}{$\mathrm{T} 4$} \\
\hline Epithelial & $r=0.07$ & $p=0.4$ & $r=0.1$ & $p=0.4$ & $r=0.5$ & $p=0.01$ \\
\hline Stromal & $r=0.2$ & $p=0.1$ & $r=0.06$ & $p=0.8$ & $r=0.3$ & $p=0.1$ \\
\hline
\end{tabular}




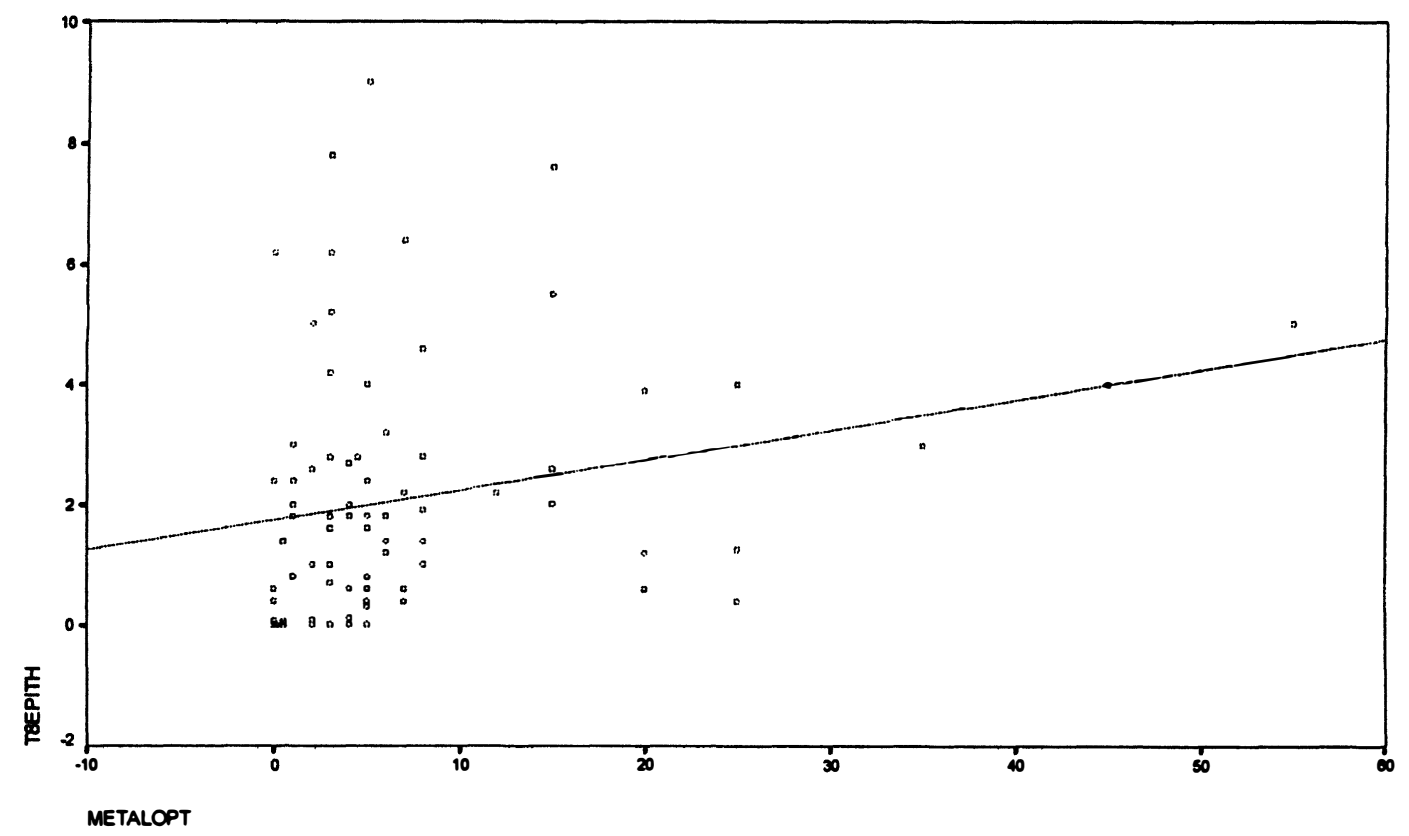

Fig. 5. Correlation between metallothionein (METALOPT) expression and T8 lymphocytes (TSE PITH) in pterygium.

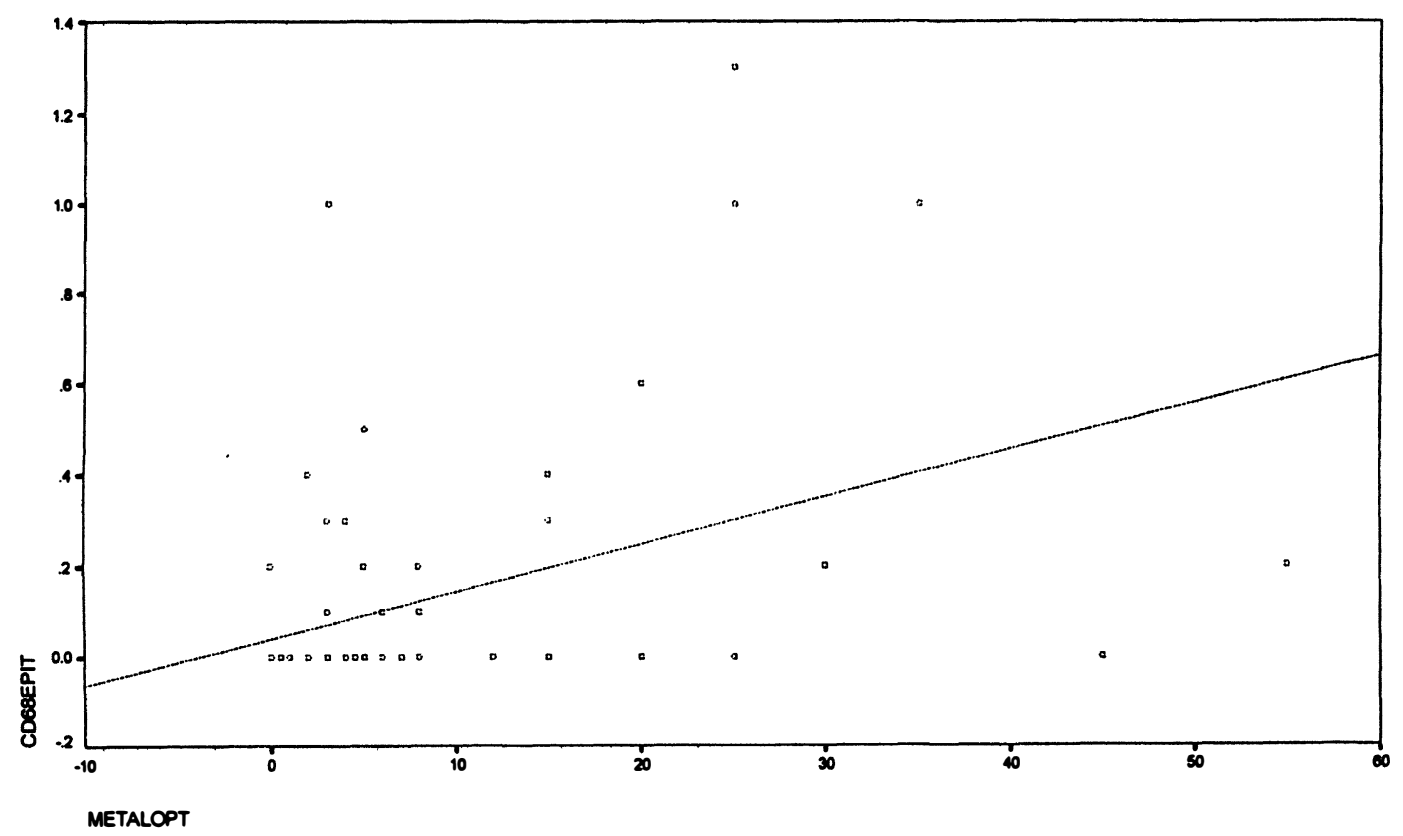

Fig. 6. Correlation between metallothionein (METALOPT) expression and epithelial macrophages (CD68) in pterygium.

correlation between MT immunopositive cells and epithelial and stromal (CD68) macrophages $(r=0.4$, $p<0.001$ and $r=0.3, p=0.04$, respectively).

Furthermore MT expression was weakly but positively correlated with lymphocyte (T8) epithelial subsets $(r=0.3, p=0.01)$. In addition a positive correlation was found between MT expression and Ki67 and PCNA score ( $r=0.5, p<0.001$ and $r=0.4, p<0.001$, respectively)

(Table 3; Figs. 5-9).

We should also mention that no statistically significant difference was found among pterygium MT expression and type of pterygium, pterygium recurrence, sex and occupation of the patients.
In pinguecula, positive correlations were not statistically significant. We noted only a trend towards positive correlation with PCNA and Ki67 score $(r=0.5$, $p=0.07$ and $r=0.5, p=0.05$, respectively) (Table 3 ).

In conjunctiva, MT expression was positively correlated with stromal macrophages (S100) and epithelial T8 lymphocytes $(r=0.4, p=0.01$ and $r=0.5$, $p=0.01$, respectively). A positive correlation between MT expression and PCNA and Ki67 score was found too $(r=0.5, p=0.04, r=0.9, p<0.001)$ (Table 3).

In all specimens PCNA expression paralleled Ki67 score, an observation which confirms the credibility of the two indices. 


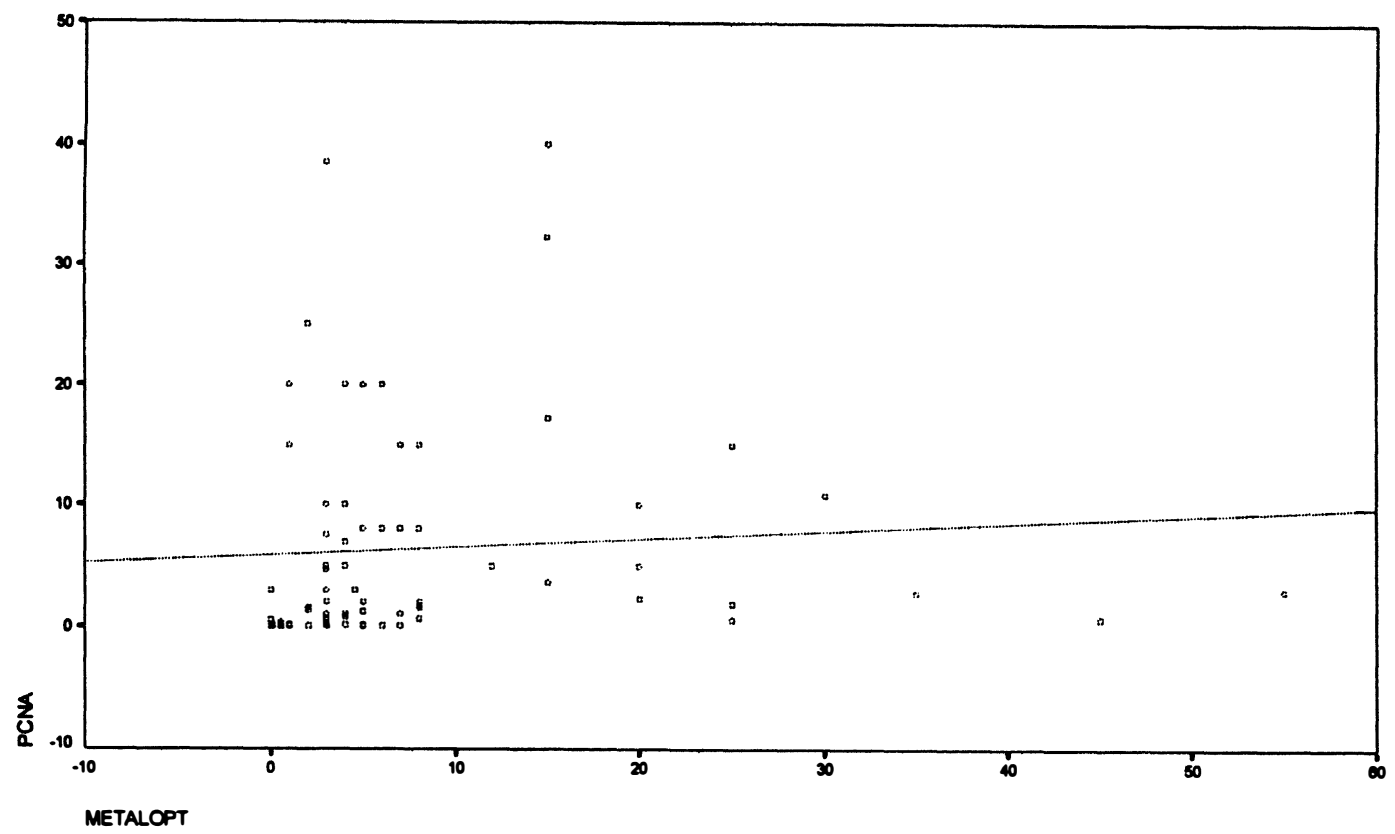

Fig. 7. Correlation between metallothionein (METALOPT) expression and PCNA in pterygium.

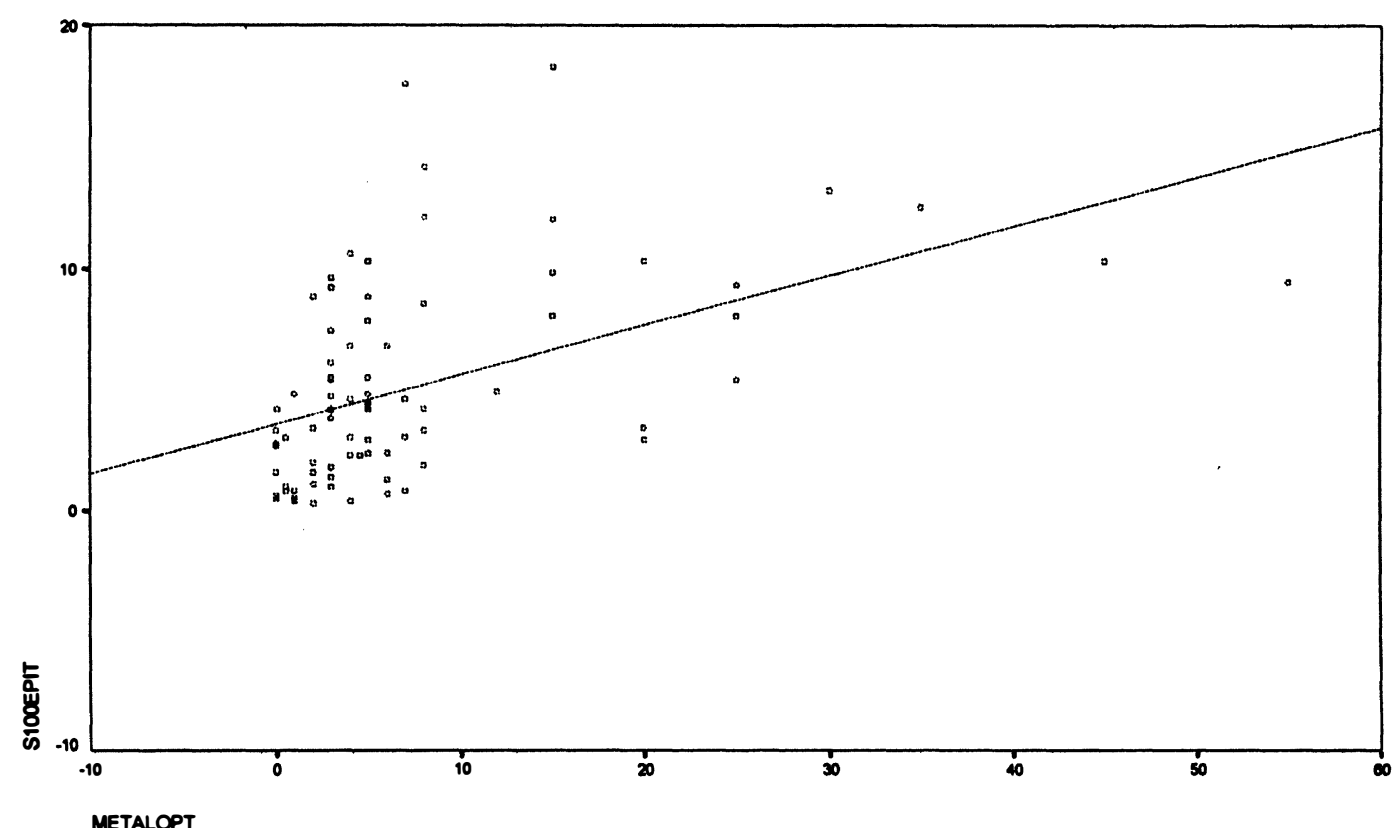

Fig. 8. Correlation between metallothionein (METALOPT) expression and Langerhans' cells (S100EPIT) in pterygium.

\section{Discussion}

The metal binding proteins known as metallothioneins are important in zinc and copper metabolism in man and animals. MT expression is readily and rapidly inducible in many tissues by a wide variety of stress factors, but normally MTs are not expressed constitutively in tissues, in amounts detectable by immunocytochemistry, except in a few specific cell types such as myoepithelial, renal and thyroid epithelial cells. ${ }^{13}$ According to our data, which comes to complement previous information about MT expression in the eye ${ }^{26,27}$ conjunctiva should be added to the catalogue of tissues in which MT genes are normally expressed constitutively. This deduction suggests possible factors that induce MT expression in conjunctival epithelium.
Previous studies have confirmed that ambient levels of UV irradiation are capable of inducing immunohistochemically detectable MT in human skin (keratinocytes and dermal fibroblasts) in vivo. ${ }^{5}$ The concurrent photoinduction of p53 tumour suppression protein after exposure of skin to UVA was also demonstrated. ${ }^{5}$ Accumulating evidence suggests that MT has a photoprotective role, but it is currently unclear whether MT functions independently to the Ha-ras cytoplasmic protein kinase pathways or is activated as an: integral part of this response. ${ }^{5}$ It is certain, though, that MT has a scavenger function for free radicals, so it may be partially responsible for the cellular protection against ionising radiation and alkylating agent cytotoxicity. ${ }^{4}$ With all the above in mind, we hypothesise that the presence of MT in epithelial cells of normal conjunctiva 


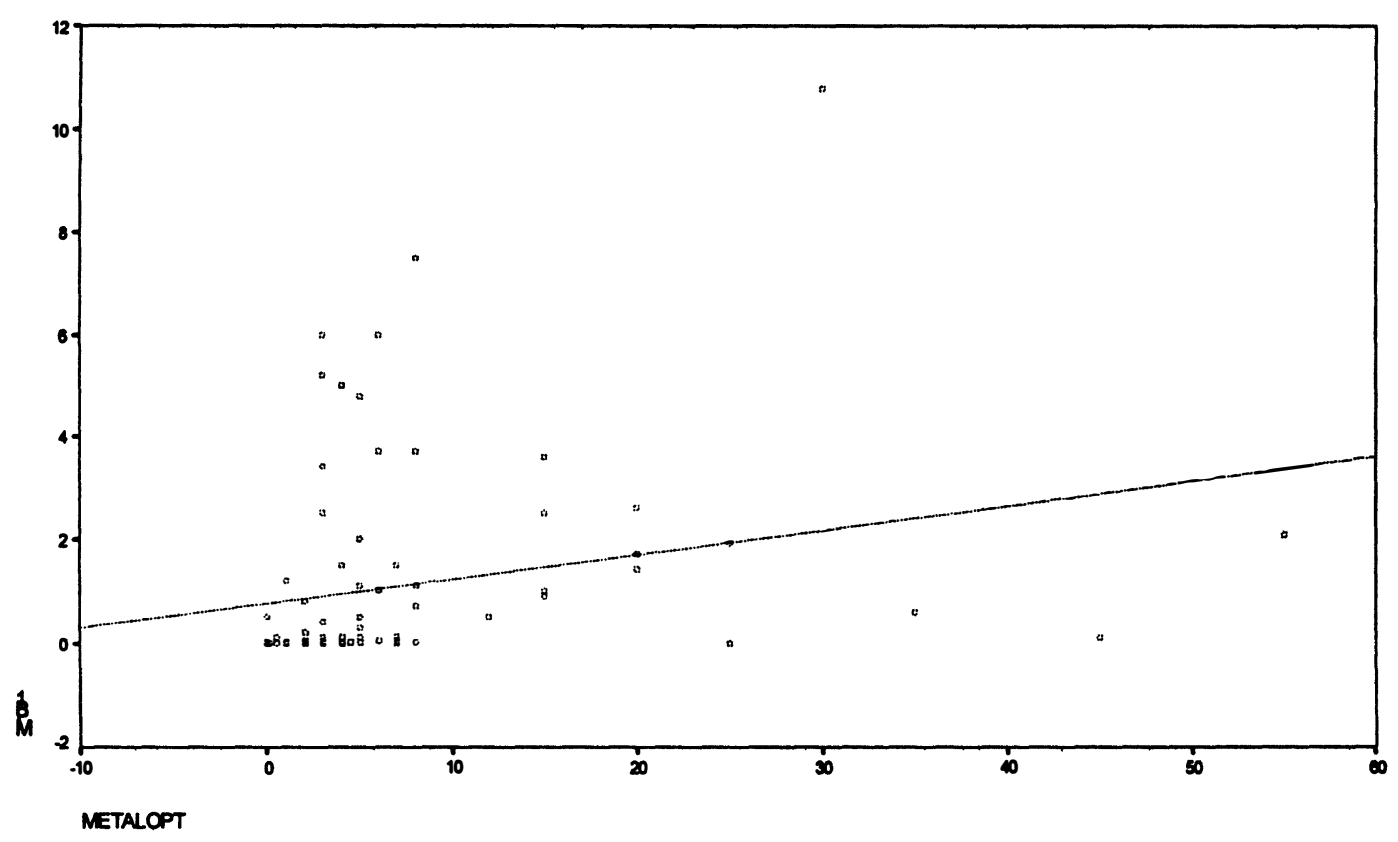

Fig. 9. Correlation between metallothionein (METALOPT) expression and Ki67 (MIB1) in pterygium.

could play a photoprotective role, contributing to the cellular SOS response to UV, which is an ancient mechanism of universal importance.

On the other hand the existence of MT expression constitutively within normal conjunctival epithelium at basal' levels may justify the lack of a kinetic increase, and the similar expression of MT in lesions such as pinguecula and pterygium.

Previous studies suggest that if cellular DNA damage is mediated by free radicals, then MT induction may take on a functional significance through its radical scavenging properties. ${ }^{5}$ This might be expected to exert an 'anti-neoplasmic' effect by limiting chromosomal instability and hence the rate of clonal evolution. ${ }^{5}$ As for pterygium, the positive correlation with chronic irradiation has long been known. ${ }^{14,15,21-23}$ UVA induces production of multiple cytokines, interferon- $\gamma^{28}$ and reactive oxygen species, derived from endogenously present chromophores such as riboflavin, porphyrins, quinones and NADPH. These cause lipid peroxidation, cell membrane damage, denaturation of proteins and DNA damage - factors which may be potentially mutagenic or lead to cell death. Nevertheless there is not only evidence that suggests cells under stress are likely to overexpress MT as a protective response to the DNAdamaging influence of hydroxyl radicals, but also findings which imply a relationship between MT and p53 expression. ${ }^{13}$ On the other hand, previous studies describing abnormal expression of $\mathrm{p} 53^{29,30}$ as well as the apoptosis-inhibiting protein bcl-2, ${ }^{30}$ in the epithelium of pterygium, suggested that pterygium is a growth disorder rather than a simple degeneration. ${ }^{29}$ Having all the data in mind, one wonders whether MT could exert an 'anti-neoplasmic' effect, through its radical scavenging properties, ${ }^{5}$ partly 'justifying' the benign or 'intermediate' characteristics of pterygium, as the lesion can be highly proliferative and invasive into the superficial cornea but never becomes corrosive or metastatic. All these hypotheses are to be tested in order to establish the possible role of MT in pterygium development.

In pterygium there is some statistically significant correlation between MT expression and immune cell scores, more with Langerhans' cells (S100) and macrophages (CD68) and less with lymphocyte subsets. The presence of immune cell subpopulations (Table 2) in pterygium is expected, as many previous studies have suggested that immunopathological mechanisms are responsible for the pathogenesis of pterygium. ${ }^{17,19,20}$ On the other hand, it is known that endogenous factors such as cytokines, which are products of immunopathological disorders, are able to induce MT expression. ${ }^{13}$ So the question that arises is whether the immune procedures in pterygium interact, more or less, with the induction of MT genes. This could be partly an alternative explanation for MT induction, specifically in pterygium, but of rather uncertain significance until there are more data available.

In addition, MT expression was positively correlated with proliferation-associated indices (PCNA, Ki67) in all three types of tissues (Table 3). Our results correspond with previous findings suggesting that MTs are often associated with cell proliferation, especially through supply of zinc ions., ${ }^{3,10}$

In conclusion, we have confirmed the presence of metallothionein in normal nasal epibulbar conjunctiva, pinguecula and pterygium. We found no significant difference in the proportion of immunopositive cells between these three tissues. We have cited our speculations about the induction mechanisms of MT and its possible role. Further investigation and data would illuminate the role and importance of this small protein in the 'cross-talking' biochemical pathways of various molecules in the eye. 


\section{References}

1. Swoo E, Lazo SJ. Neocytoplasmic functionality of metallothionein. Cancer Res 1997;57:4236-41.

2. Fresno M, Wu W, Rodriguez JM, Nadji M. Localization of metallothionein in breast carcinomas: an immunohistochemical study. Virchows Arch [A] 1993;423:215-9.

3. National Cancer Institute workshop on the possible roles of metallothionein in carcinogenesis. Meeting report. Cancer Res 1993;53:922-5.

4. Zelger B, Hittmair A, Schir M, Ofner C, Ofner D, Fritsch PO, et al. Immunohistochemically demonstrated metallothionein expression in malignant melanoma. Histopathology 1993;23:257-64.

5. Anstey A, Marks R, Long C, Navabi H, Pearse A, WynfordThomas $\mathrm{D}$, et al. In vivo photoinduction of metallothionein in human skin by ultraviolet irradiation. J Pathol 1996;178:84-8.

6. Jasani B, Campbell F, Navabi H, Schmid K, et al. Clonal overexpression of metallothionein is induced by somatic mutation in morphologically normal colonic mucosa. J Pathol 1998;184:144-7.

7. Schmid K, Ellis IO, Gee J, Darke BM, Lees WR, Kay J, et al. Presence and possible significance of immunohistochemically demonstrable metallothionein overexpression in primary invasive ductal carcinoma of the breast. Virchows Arch [A] 1993;422:153-9.

8. Fuentealba IC, Mullins JE. Immunohistochemical demonstration of metallothionein in benign and malignant canine mammary tumors. Histol Histopathol 1999;14:51-61.

9. Ofner D, Maier H, Riedmann B, Bammer T, Rumer A, Winde $\mathrm{G}$, et al. Immunohistochemical metallothionein expression in colorectal adenocarcinoma: correlation with tumor stage and patient survival. Virchows Arch 1994;425:491-7.

10. Fuller CE, Elmes M, Jasani B. Age related changes in metallothionein, copper, copper-associated protein and lipofuscin in human liver: a histochemical and immunohistochemical study. J Pathol 1990;161:167-72.

11. Sunardhi-Widyaputra S, Vanden Oord JJ, Van Houdt K, Deley M, Van Damme B. Identification of metallothionein and parathyroid hormone-related peptide (PTHrP)-positive cells in salivary gland tumors. Path Res Pract 1995;191:1092-8.

12. Wood DP, Eric Klein Jr, Fair WR, Chaganti RSK. Metallothionein gene expression in bladder cancer exposed to cisplatin. Mod Pathol 1993;6:33-5.

13. Douglas-Jones AG, Schmid KD, Bier B, Horgan K, Lyons K, Dallimore ND, et al. Metallothionein expression in duct carcinoma in situ of the breast. Hum Pathol 1995;26:217-22.
14. Taylor HR. Ocular effects of UV-B exposure. Doc Ophthalmol 1995;88:285-93.

15. Mora DJ, Hollows FC. Pterygium and ultraviolet radiation: a positive correlation. Br J Ophthalmol 1984;68:343-6.

16. Hill JC, Maske R. Pathogenesis of pterygium. Eye 1989;3:218-26.

17. Lin L, De Wang Y. Immunological studies on the pathogenesis of pterygium. Chinese Med Sci J 1993;8:81-8.

18. Orde Peckar C. The etiology and histo-pathogenesis of pterygium: a review of the literature and a hypothesis. Doc Ophthalmol 1972;31:141-57.

19. Orgen D, Pinkerton MD, Voshitsugi H, Shigemura LA. Immunologic basis for the pathogenesis of pterygium. Am J Ophthalmol 1984;98:225-8.

20. Solomon AS. [Letter]. Am J Ophthalmol 1985;216.

21. Kwork LS, Coroneo MT. A model for pterygium formation. Cornea 1994;13:219-24.

22. Threffal TJ. Sun exposure and pterygium of the eye: a dose response curve. Am J Ophthalmol 1999;128:280-7.

23. Saw SM, Tan D. Pterygium: prevalence, demography and risk factors. Ophthalmic Epidemiol 1999;6:219-28.

24. Ozone depletion quickens [editorial]. Lancet 1991;337:1132-3.

25. Hsu SM, Raine L, Fanger H. Use of avidin-biotin peroxidase complex $(\mathrm{ABC})$ in immunoperoxidase techniques: a comparison between $\mathrm{ABC}$ and unlabelled antibody (PAP) procedures. J Histochem Cytochem 1981;29:577-80.

26. Nishimura H, Nishimura N, Kobayashi S, Tohyama C. Immunohistochemical localization of metallothionein in the eye of rats. Histochemistry 1991;95:535-9.

27. Laueryns B, Van den Oord JJ, Missotten L. The transitional zone between limbus and peripheral cornea: an immunohistochemical study. Invest Ophthalmol Vis Sci 1993;34:1991-9.

28. Kennedy M, Kim KH, Harten B, Brown J, Planck S, Meshul $\mathrm{C}$, et al. UVA irradiation induces the production of multiple cytokines by human corneal cells. Invest Ophthalmol Vis Sci 1997;38:2483-91.

29. Tan DT, Lim AS, Goh HS, et al. Abnormal expression of the p53 tumor suppressor gene in the conjunctiva of patients with pterygium. Am J Ophthalmol 1997;123:404-5.

30. Tan DT, Tang WY, Liu YP, Goh HS, Smith DR. Apoptosis and apoptosis related gene expression in normal conjunctiva and pterygium. Br J Ophthalmol 2000;84:212-6.

31. Hainaut $P$, Milner J. A structural role for metal ions in the 'wild type' conformation of the tumor suppressor protein p53. Cancer Res 1993;53:1739-42. 